\title{
Intraperitoneal and intra-nasal vaccination of mice with three distinct recombinant Neospora caninum antigens results in differential effects with regard to protection against experimental challenge with Neospora caninum tachyzoites
}

\author{
K. DEBACHE ${ }^{1}$, C. GUIONAUD ${ }^{2}$, F. ALAEDDINE ${ }^{2}$ and A. HEMPHILL ${ }^{1} *$ \\ ${ }^{1}$ Institute of Parasitology, Vetsuisse Faculty, University of Berne, Länggass-Strasse 122, CH-3012 Berne, Switzerland \\ ${ }^{2}$ Institute of Veterinary Pharmacology $\Xi^{\circ}$ Toxicology, Vetsuisse Faculty, University of Berne, Länggass-Strasse 124, \\ CH-3012 Berne, Switzerland
}

(Received 1 May 2009; revised 30 Fune and 23 Fuly 2009; accepted 24 Fuly 2009; first published online 16 October 2009)

\begin{abstract}
SUMMARY
Recombinant NcPDI(recNcPDI), NcROP2(recNcROP2), and NcMAG1(recNcMAG1) were expressed in Escherichia coli and purified, and evaluated as potential vaccine candidates by employing the $\mathrm{C} 57 \mathrm{Bl} / 6$ mouse cerebral infection model. Intraperitoneal application of these proteins suspended in saponin adjuvants lead to protection against disease in $50 \%$ and $70 \%$ of mice vaccinated with recNcMAG1 and recNcROP 2 , respectively, while only $20 \%$ of mice vaccinated with recNcPDI remained without clinical signs. In contrast, a $90 \%$ protection rate was achieved following intra-nasal vaccination with recNcPDI emulsified in cholera toxin. Only 1 mouse vaccinated intra-nasally with recNcMAG1 survived the challenge infection, and protection achieved with intra-nasally applied recNcROP2 was at $60 \%$. Determination of cerebral parasite burdens by real-time PCR showed that these were significantly reduced only in recNcROP2-vaccinated animals (following intraperitoneal and intra-nasal application) and in recNcPDI-vaccinated mice (intra-nasal application only). Quantification of viable tachyzoites in brain tissue of intra-nasally vaccinated mice showed that immunization with recNcPDI resulted in significantly decreased numbers of live parasites. These data show that, besides the nature of the antigen, the protective effect of vaccination also depends largely on the route of antigen delivery. In the case of recNcPDI, the intra-nasal route provides a platform to generate a highly protective immune response.
\end{abstract}

Key words: Recombinant Neospora caninum antigen, tachyzoites, vaccination, mice, intraperitoneal, intra-nasal.

\section{INTRODUCTION}

Neospora caninum is an apicomplexan parasite that causes abortion and stillbirth in cattle and neuromuscular disease in dogs. Many other species can also be affected. The parasite has emerged as a significant veterinary public health problem, since it has been shown to represent the most important abortion-causing pathogen in bovines, responsible for economic losses to the cattle industry worldwide (McAllister et al. 1998; Gondim, 2004; Dubey et al. 2007). Protection of fetal death in cattle has been achieved experimentally by immunization of dams with live $N$. caninum tachyzoites (Williams et al. 2007). However, at the present time, there is no nonlive vaccine capable of inducing complete protective immunity against neosporosis in cattle.

\footnotetext{
* Corresponding author: Andrew Hemphill, Institute of Parasitology, Vetsuisse Faculty, University of Berne, Länggass-Strasse 122, CH-3012 Berne, Switzerland. Tel. +41316312384. Fax +41316312477. E-mail: hemphill@ipa.unibe.ch
}

Mice have been widely used as laboratory models for proof-of-concept studies involving vaccine candidates, in spite of the fact that murines and bovines exhibit somewhat different immunological characteristics (reviewed by Hemphill et al. 2006; Innes, 2007; Innes and Mattsson, 2007). Infection with killed tachyzoite lysate prevents foetal infection in mice (Liddell et al. 1999), but not in cattle. A commercialized vaccine, consisting of tachyzoite lysate (Neoguard ${ }^{\mathrm{TM}}$ ), is currently marketed in the US, but efficacy data are difficult to interpret (Williams and Trees, 2006; Innes and Vermeulen, 2006).

To date, the major portion of antigens that have been investigated as subunit vaccine candidates are involved in tachyzoite-host cell interactions, and are localized either on the surface of tachyzoites, or within secretory organelles such micronemes, rhoptries and dense granules (reviewed by Hemphill et al. 2006). Various strategies have been used to enhance the post-vaccination immune response, such as application of multiple recombinant antigens in one shot (Cho et al. 2005; Ellis et al. 2008), different adjuvants and dosages, various formulations and 
different routes of administration (Innes and Mattsson, 2007).

For non-live vaccines such as recombinant antigens, the classical application routes are either intraperitoneal (i.p.) or subcutaneous (s.c.) injection. In this study, we have investigated whether changing the route of application will alter the efficacy of 3 putative $N$. caninum vaccine candidates in terms of cerebral neosporosis in mice. First, NcROP2 is a $N$. caninum rhoptry protein, and pre-incubation of parasites with antibodies directed against NcROP2 and of host cells with recombinant recNcROP2, inhibited host cell invasion by $N$. caninum tachyzoites in vitro (Debache et al. 2008). Secondly, NcPDI, a protein disulfide isomerase, is partially found within micronemes and exposed on the surface of N. caninum tachyzoites, and anti-NcPDI antibodies also impair adhesion of parasites to the host cell surface in vitro (Naguleswaran et al. 2005). In addition, inhibition of NcPDI activity with a number of sulfhydryl blockers and the PDI inhibitor bacitracin also have a negative influence on the interaction of $N$. caninum tachyzoites with their host cells (Müller et al. 2008). Third, NcMAG1 is located within dense granules in tachyzoite-stage parasites, which incorporates into the cyst wall during tachyzoite-tobradyzoite stage conversion, similar to what has been described for NcGRA2 and NcGRA7 (Vonlaufen et al. 2004).

We here show that intra-nasal application of a vaccine based on recNcPDI produced fundamentally improved outcomes in terms of occurrence of clinical signs, parasite burden and serological responses upon challenge infection. In contrast, intra-nasal vaccination with recNcMAG1 had a negative impact on protection and, in the case of recNcROP2, no substantial differences were noted.

\section{MATERIALS AND METHODS}

Unless otherwise stated, all cell culture reagents were supplied by Gibco-BRL (Zurich, Switzerland) and chemicals were purchased from Sigma (St Louis, MO, USA).

\section{Neospora caninum tachyzoite culture and purification}

Vero cells and human foreskin fibroblasts (HFF) were routinely cultured in RPMI-1640 medium supplemented with $10 \%$ heat-inactivated FCS, 2 mM glutamine, $50 \mathrm{U}$ of penicillin $/ \mathrm{ml}$ and $50 \mu \mathrm{g}$ of streptomycin $/ \mathrm{ml}$ at $37^{\circ} \mathrm{C} / 5 \% \mathrm{CO}_{2}$ in tissue culture flasks. Cultures were passaged at least once per week. $N$. caninum tachyzoites of the $\mathrm{Nc1}$ strain (Dubey et al. 1988) were maintained by serial passages in Vero cells or HFF during which time FCS was replaced with $5 \%$ immunoglobulin $\mathrm{G}(\mathrm{IgG})$-free horse serum (HS). Parasites were harvested as described previously by Hemphill et al. (1996). Infected cells were trypsinized, washed twice in cold RPMI-1640 medium, and the resulting pellet was resuspended in $2 \mathrm{ml}$ of cold RPMI-1640 medium. Cells were repeatedly passed through a $25 \mathrm{G}$-needle and liberated tachyzoites were purified by passage through Sephadex-G25 columns (Amersham Biosciences, Otelfingen, Switzerland), previously equilibrated with cold RPMI-1640 medium. The eluted parasites were centrifuged at $600 \mathrm{~g} / 10 \mathrm{~min} / 4{ }^{\circ} \mathrm{C}$, resupended in cold RPMI-1640 medium, and counted in a Neubauer chamber. Viability assessment was done by Trypan blue exclusion, and in all experiments, over $95 \%$ of the tachyzoites were viable.

\section{Expression and purification of recombinant $N c P D I$ (recNcPDI), NcROP2 (recNcROP2), and NcMAG1 (recNcMAG1)}

RecNcPDI was cloned into the His-tag expression vector pET151 and expressed in Escherichia coli BL21 Star (Invitrogen, Carlsbad, Canada) as previously described (Müller et al. 2008). RecNcROP2 was cloned into pQE-30 (Qiagen, Hilden, Germany) as described by Debache et al. 2008, 2009), and expressed in E. coli BL21 (Novagen-EMD Biosciences, Madison, WI, USA) harbouring the pREP4 repressor plasmid (Qiagen).

The cDNA sequence coding for the NcMAG1 antigen was retrieved in GenBank under the Accession number EF580924. The deduced protein sequence is comprised of 456 amino acids, and shares $54 \%$ identity to the homologous TgMAG1 protein (Parmley et al. 1994). RecNcMAG1 cloning was performed by isolation of total RNA from $3 \times 10^{6}$ purified N. caninum tachyzoites using Trizol reagent (Invitrogen, Carlsbad, CA) according to the manufacturer's instructions. First strand cDNA synthesis reactions were performed for $1 \mathrm{~h}$ at $42{ }^{\circ} \mathrm{C}$ in a $20 \mu \mathrm{l}$ reaction mixture containing $2 \mu \mathrm{g}$ of total $\mathrm{RNA}, 1 \times$ first-strand buffer (Invitrogen), $0.5 \mathrm{~mm}$ of each dNTP (Endotell, Allschwil, Switzerland), $10 \mathrm{mM}$ dithiothreitol, $20 \mathrm{U}$ of RNasin RNase inhibitor (Promega, Madison, WI), 200 U of SuperScript II reverse transcriptase (Invitrogen). A portion of NcMAG1 (aa 31-394, numbering according to the precursor protein) was amplified by RT-PCR using MAG1-BamHI-F (5'-GGATCCCAAAGGGTGCCTCGC'TACCC-3') and MAG1-SmaI-R (5'-CCCGGGTTATTCCTCCACTATTTCGT-

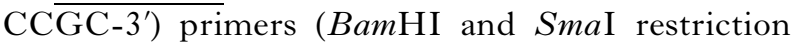
sites underlined). The PCR product was cloned into pCR blunt II TOPO (Invitrogen), verified by sequencing and the BamHI-SmaI MAG1 insert subcloned into pQE-30 (Qiagen, Hilden, Germany) using the XL1-Blue strain (Stratagene, La Jolla, CA, USA) as a recipient. The resulting pQE-30-MAG1 expression vector was used to transform $E$. coli BL21 
(Novagen-EMD Biosciences, Madison, WI) harbouring the pREP4 repressor plasmid (Qiagen). To express the fusion protein, 11 of $2 \times$ YT medium (per litre: $16 \mathrm{~g}$ bacto-tryptone, $10 \mathrm{~g}$ bacto-yeast extract, and $5 \mathrm{~g} \mathrm{NaCl}$ ), pre-warmed to $37^{\circ} \mathrm{C}$ and supplemented with carbenicillin and kanamycin (Sigma; 100 and $25 \mu \mathrm{g} / \mathrm{ml}$, respectively), was inoculated with $10 \mathrm{ml}$ of an overnight starter culture grown in the same medium. When the culture reached an OD of $0 \cdot 5$ at $\lambda=600 \mathrm{~nm}$, isopropyl- $\beta$-D-1-thiogalactopyranoside (Sigma) was added to $1 \mathrm{~mm}$ and expression was carried on for $3 \mathrm{~h}$ at $37^{\circ} \mathrm{C}$. Bacteria were harvested by centrifugation and disrupted by sonication.

Purification of recombinant His-tagged proteins was performed under non-denaturing conditions for recNcPDI and recNcMAG1 (Müller et al. 2008) and denaturing conditions for recNcROP2 (Debache et al. 2008), using Protino Ni-IDA columns (Macherey-Nagel, Düren, Germany), as recommended by the manufacturer. The purified recombinant proteins were analysed by SDS-PAGE and Western blotting, and the protein concentrations were measured employing the Bio-Rad protein assay using acetylated BSA as a standard. Following dialysis into PBS, the recombinant proteins were stored at $-80{ }^{\circ} \mathrm{C}$ prior to use.

\section{Immunization and challenge infection}

Female C57Bl/6 mice (6 weeks of age) were purchased from Charles River Laboratories (Sulzheim, Germany) and were housed under conventional day/ night conditions according to the standards set up by the animal welfare legislation of the Swiss Veterinary Office. Two independent experiments, one after the other, were carried out under the same conditions, with virtually identical outcomes, and the results of the second experimental trial are shown.

At the age of 8-9 weeks, mice were randomly distributed into 10 experimental groups of 10 mice each, and the serological status (Neospora-negative) was checked by enzyme-linked immunosorbent assay (ELISA). Mice in groups $1-5$ were treated by i.p. injection; mice in group 1 received $100 \mu 1$ of PBS each (i.p. infection control), group 2 received $100 \mu 1$ saponin adjuvant (SAP) at $100 \mu \mathrm{g} / \mathrm{ml}$, group 3 received $10 \mu \mathrm{g}$ of recNcPDI in SAP, group 4 received $10 \mu \mathrm{g}$ recNcROP2 in SAP, group 5 received $10 \mu \mathrm{g}$ recNcMAG1 in SAP. Mice in groups 6-10 were treated by i.n. application through the nares, which was performed under mild isoflurane anaesthesia. Mice in group 6 received $100 \mu \mathrm{l}$ of PBS/mouse (i.n. infection control), group 7 received $20 \mu \mathrm{l}$ of cholera toxin adjuvant $(\mathrm{CT})$ at $250 \mu \mathrm{g} / \mathrm{ml}$, group 8 received $10 \mu \mathrm{g} \mathrm{recNcPDI} /$ mouse in $\mathrm{CT}$, group 9 received $10 \mu \mathrm{g}$ recROP2 in $\mathrm{CT}$, group 10 received $10 \mu \mathrm{g}$ recNcMAG1 in $\mathrm{CT}$. These procedures were carried out on days 1, 15 and 30 . We have not included a nonvaccinated and non-treated group in these trials, since in several similar vaccine trials carried out to date no spontaneous deaths of mice occurred under the conditions used (Cannas et al. 2003a,b; Alaeddine et al. 2005; Srinivasan et al. 2007; Debache et al. 2008).

On day 46 all animals were challenged by i.p. inoculation of $1 \times 10^{6}$ freshly purified $N$. caninum tachyzoites. On day 74 , the experiment was terminated and mice were euthanized by $\mathrm{CO}_{2}$ asphyxiation. Those animals exhibiting clinical signs of neosporosis (ruffled coat, apathy, hind limb paralysis) prior to day 74 were euthanized at the onset of these signs. From each animal, blood was drawn by cardiac puncture for serological assays, brains were dissected under aseptic conditions and the tissue immediately frozen at $-20^{\circ} \mathrm{C}$.

Brains from the mice that were vaccinated intranasally were divided into the 2 hemispheres. One hemisphere, destined for the isolation of genomic DNA and subsequent quantitative assessment of parasite burden by real-time PCR (Müller et al. 2002) was immediately frozen at $-20{ }^{\circ} \mathrm{C}$. The other hemisphere, destined for RNA isolation, cDNA synthesis and quantitative assessment of viable parasites by real-time PCR on cDNA was hashed in $500 \mu$ l of QIAzol ${ }^{\mathrm{TM}}$ Lysis Reagent (Qiagen) with a small mortar in dry-ice before being frozen at $-20^{\circ} \mathrm{C}$.

\section{Serology}

Individual blood samples including pre-immune sera and post-immunization sera (taken prior to infection $=\mathrm{BI}$ ) were obtained from the tail vein, and the final blood samples (post-infection sera=PI) were obtained by cardiac puncture post-euthanasia. To evaluate the humoral immune response, samples were analysed for $N$. caninum-specific immunoglobulin $\mathrm{G}$ ( $\mathrm{IgG})$, IgG1, IgG2a and immunoglobulin A (IgA) by ELISA, employing somatic antigen extracts from $N$. caninum tachyzoites obtained from cell culture (Nc-extract). Nc-extract was prepared by subjecting tachyzoites to 3 freeze-thaw cycles followed by sonication as described by Alaeddine et al. (2005). Cellular debris was removed by centrifugation, and the protein concentration in the supernatant was measured employing the BioRad protein assay using acetylated bovine serum albumin (BSA) as a standard (Debache et al. 2008). To carry out the ELISAs, 96-well plates (Maxisorp, Wiesbaden, Germany) were coated overnight at $4{ }^{\circ} \mathrm{C}$ with $100 \mu \mathrm{l}$ of Nc-extract $(7 \mu \mathrm{g} / \mathrm{ml})$, diluted in $0 \cdot 1 \mathrm{M}$ $\mathrm{NaHCO}_{3}-\mathrm{Na}_{2} \mathrm{CO}_{3}$, pH 9. To block non-specific binding of antibodies, plates were incubated for $2 \mathrm{~h}$ with $200 \mu \mathrm{l}$ of PBS containing $3 \%$ BSA and $0 \cdot 2 \%$ Tween 20. Serum samples were diluted $1: 50$ in PBS containing $0 \cdot 3 \% \mathrm{BSA} / 0 \cdot 2 \%$ Tween 20 (BSAT) and incubated for $2 \mathrm{~h}$ at $20^{\circ} \mathrm{C}$. After 3 washes with BSAT, anti-mouse $\operatorname{IgG}$ conjugated to alkaline 
phosphatase (Promega, Madison, WI, USA), or goat anti-mouse alkaline phosphatase-IgG1 or IgG2aconjugates (SouthernBiotech, Birmingham, USA) and goat anti-mouse IgA-alkaline phosphatase conjugates (Sigma, St Louis, MO, USA) were added, respectively, at dilution of $1: 1000$ in BSAT. Conjugates were incubated for $2 \mathrm{~h}$ at $20{ }^{\circ} \mathrm{C}$. Following 3 washes in BSAT, the wells were subsequently incubated with $100 \mu \mathrm{l}$ of $1 \mathrm{mg} / \mathrm{ml} p$-nitrophenylphosphate-disodium in $10 \%$ diethanolamine containing $0.5 \mathrm{mM} \mathrm{MgCl}_{2}, \mathrm{pH} 9 \cdot 8$. After allowing the colour to develop for $30 \mathrm{~min}$ at $20{ }^{\circ} \mathrm{C}$, the absorbance values $(405 \mathrm{~nm})$ were read in a tunable microplate reader (Dynatech, Embrach, Switzerland).

\section{Quantitative real-time PCR using cerebral genomic DNA}

The conventional Neospora-specific quantitative real-time PCR (Müller et al. 2002) from genomic DNA was performed as previously described (Srinivasan et al. 2007; Debache et al. 2008). Brain DNA extraction was performed using the DNeasy ${ }^{\circledR}$ Blood \& Tissue Kit (Quiagen) (Müller et al. 2002). The DNA concentrations in all brain samples were determined by UV spectrophotometry, and were adjusted to $100 \mathrm{ng} / \mu \mathrm{l}$ with sterile Dnase-free water. The assessments of $N$. caninum tachyzoite loads were performed using the LightCycler ${ }^{\mathrm{TM}}$ Instrument (Roche Diagnostic, Basel, Switzerland). The parasite counts were calculated by interpolation from a standard curve with DNA equivalents from 1000, 100 and 10 parasites included in each run.

\section{Quantitative real-time PCR using cerebral cDNA}

To quantify the viable tachyzoites in brain samples, NcGRA2-RT-PCR was performed using the corresponding other hemisphere from each mouse (Strohbusch et al. 2008a,b). Then $200 \mu$ l of chloroform was added to all brain samples stored in $\mathrm{QIAzol}^{\mathrm{TM}}$, and the upper phase, obtained after vigorously vortexing and centrifuging the sample for $2 \mathrm{~min}$ at $10000 \mathrm{~g}$, was transferred to a new tube. Ethanol $(70 \% \mathrm{v} / \mathrm{v})$ was added, the sample mixed by pipetting, and loaded onto RNeasy ${ }^{\circledR}$ mini kit (Qiagen) spin columns and total RNA isolation was performed according to the standard protocol. RNA was eluted in RNase-free water and boiled at $95{ }^{\circ} \mathrm{C}$ for 3 min. Using the Omniscript ${ }^{\mathbb{R}}$ Reverse Transcription kit (Qiagen) and $0.5 \mu \mathrm{g}$ random primers (Promega, Wallisellen, Switzerland), cDNA synthesis was performed according to the standard protocol for first-strand cDNA synthesis from $1000 \mathrm{ng}$ of RNA (measured and adjusted by NanoDrop ${ }^{\mathrm{TM}}$, Thermo Scientific, Delaware, USA). Finally, cDNA was boiled at $95{ }^{\circ} \mathrm{C}$ for $3 \mathrm{~min}$ and frozen at $-80{ }^{\circ} \mathrm{C}$ prior to use. The Nc-GRA2-real time PCR was performed according to Strohbusch et al. $(2008 a, b)$. The parasite counts were calculated by interpolation from a standard curve with cDNA equivalents from 1000, 100 and 10 parasites included in each run.

\section{Statistics}

The cerebral parasite loads in immunized mice, and the numbers of viable tachyzoites expressing NcGRA2 in the intra-nasally vaccinated groups, were statistically assessed by Kruskal-Wallis multiple comparison, followed by Duncan's multiple range test to compare between 2 particular groups. The differences in survival rates were checked by the Kaplan-Meier survival method followed by log-rank statistical test. The comparison of serological responses between the different treatment groups was done by ANOVA test. When comparing the samples from the same group at different time-points (BI and $\mathrm{PI})$, paired Student's $t$-test, was used, and unpaired Student's $t$-test was used when comparing animals from different groups at the same time-point. All analyses of variances were done using the NCSS Quick Start@ 2001 software.

\section{RESULTS}

\section{Clinical signs of neosporosis caused by parasite challenge following vaccination via intra-peritoneal and intra-nasal routes}

Following vaccination and challenge infection with $N$. caninum tachyzoites, mice were carefully monitored for the occurrence of clinical signs of neospororis such as apathy, ruffled hair, loss of body weight, rounded back and circular movements. All mice in the 2 control groups (treated with PBS only) succumbed to infection latest at day 21 p.i. (Fig. 1). When only the adjuvants (either saponin or cholera toxin) were applied, all mice died latest on days 25 and 27, respectively. Upon immunization by the i.p. route, recNcROP2 and recNcMAG1 provided protection in 7 and 5 out of 10 mice, respectively, that did not develop any clinical signs. In contrast, only 2 mice out of 10 that had been vaccinated by i.p. inoculation with recNcPDI survived until day 28 p.i. (Fig. 1A). Intra-nasal vaccination with recNcROP2 proved to provide a similar degree of protection (6 out of 10 survivors) as vaccination through the intraperitoneal route. However, the situation was different for the other 2 antigens. Only 1 out of 10 recNcMAG1-vaccinated mice survived until 28 days p.i., and when recNcPDI was applied intra-nasally, 9 out of 10 mice survived and only 1 animal succumbed to infection on day 20 (Fig. 1B). No histological assessments were made to assess inflammation within the cerebral tissues of these mice. 
A
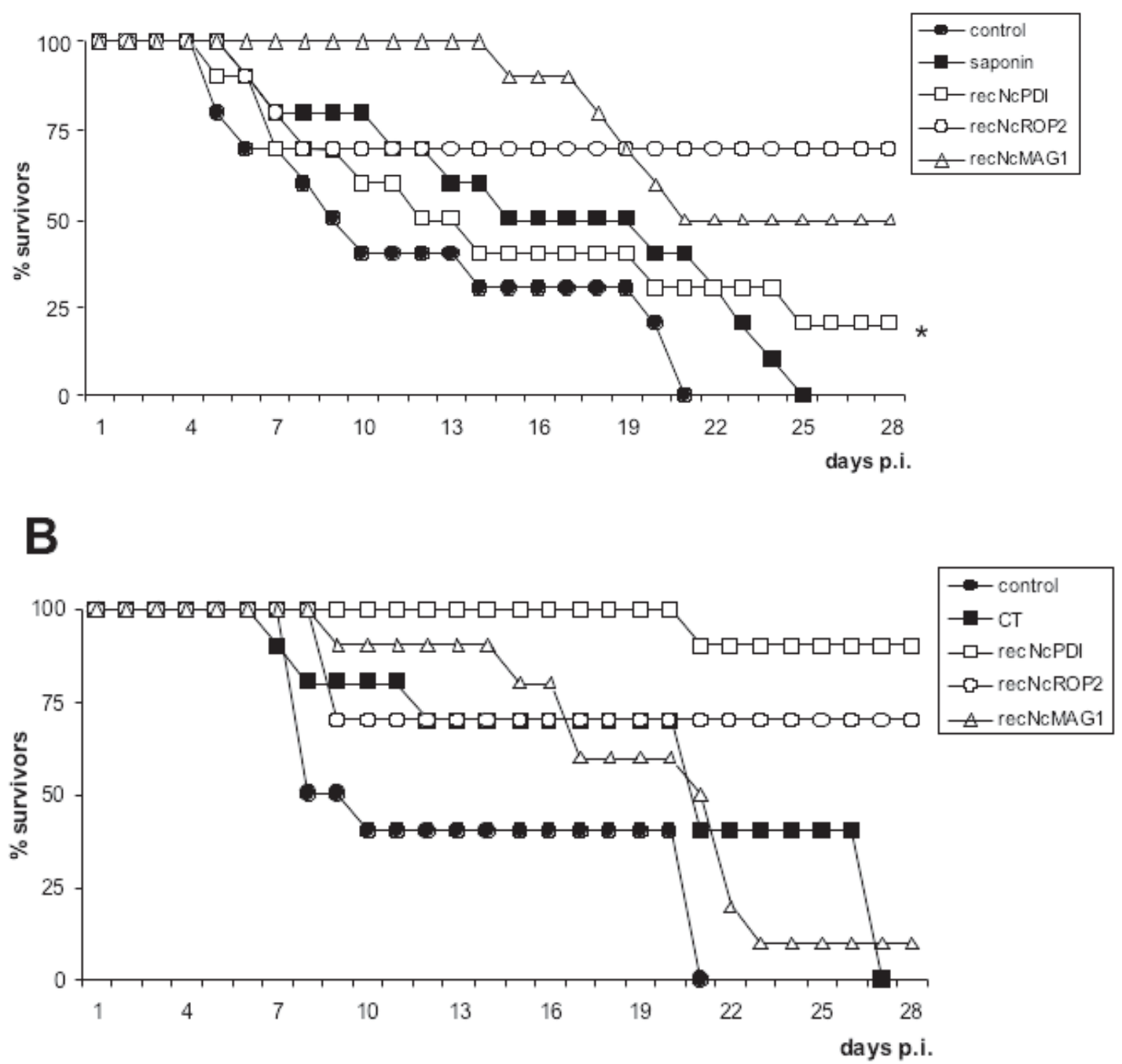

Fig. 1. Survival curves of the different treatment groups following experimental infection with $1 \times 10^{6}$ Neospora caninum tachyzoites. (A) Mice were vaccinated intra-peritoneally either with PBS (control), saponin adjuvants, recNcPDI, recNcROP2 or recNcMAG1 in saponin adjuvants. (B) Mice were vaccinated intra-nasally with PBS (control), cholera toxin, recNcPDI, recNcROP2 or recNcMAG1 resuspended in cholera toxin. The asterisk in (A) indicates the statistical difference $(P<0 \cdot 05)$ of the recNcPDI-vaccinated group compared with the group vaccinated with recNcROP2 in intraperitoneally vaccinated mice. Note the high protective effect $(90 \%)$ achieved with the intra-nasally applied recNcPDI vaccine in (B).

Parasite burden in brain tissues of vaccinated mice assessed by N. caninum-specific real-time PCR

Cerebral parasite burdens in the different treatment groups were determined by quantitative real-time PCR (Fig. 2). There was no significant difference in parasite load between intra-peritoneal and intra-nasal application of either PBS or adjuvants in the 2 control groups. These values were comparable to respective parasite loads obtained in the recNcMAG1vaccinated mice. In contrast, parasite load in recNcROP2-vaccinated mice was significantly lower $(P<0.05)$ compared to the adjuvant control groups by both, intraperitoneal and intra-nasal application.

Brain tissues of recNcPDI-vaccinated mice that had been immunized intraperitoneally did not exhibit any differences in parasite load compared to the PBS-treated and saponin-treated control groups, but brain tissues of mice that had been vaccinated with recNcPDI through the intra-nasal route exhibited values that were in the similar lower range as for the 2 recNcROP2-vaccinated groups $(P<0 \cdot 01)$. Thus, recNcPDI has a protective effect when applied intra-nasally, but not when applied intraperitoneally.

Quantification of viable N. caninum tachyzoites in infected brain hemispheres by GRA2-specific $R T$ real-time $P C R$

In order to further study the effects of intra-nasal vaccination on parasite viability, we employed a 


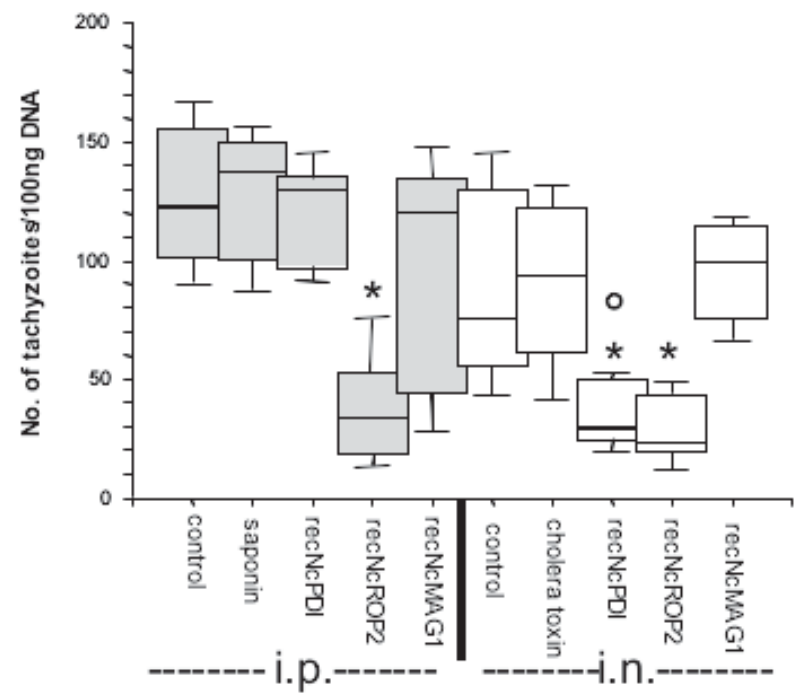

Fig. 2. Cerebral parasite load in the different treatment groups as assessed by real-time PCR (amplification of genomic DNA). The corresponding experimental groups of intra-peritoneally (i.p.) and intransally (i.n.) vaccinated mice are directly compared. Statistically significant differences are indicated. $*=P<0.05$ as compared to the corresponding adjuvant-treated group, ${ }^{\circ}=P<0.05$, as compared to the recNcPDI-treated group of intraperitoneally vaccinated mice. Note the strongly reduced cerebral parasite burden in the group receiving the intra-nasally applied recNcPDI vaccine. Error bars indicate S.D.

recently developed NcGRA2-specific RT real-time PCR (Strohbusch et al. 2008 a,b), which allows quantification of the number of viable tachyzoites in brain tissue samples of the different experimental groups. The rational behind this assay is that NcGRA2-mRNA will only be detected when viable parasites are present, since mRNA is rapidly degraded upon cell death. In contrast, genomic DNA is inherently more stable, thus, in the case where nonviable organisms are present in the brain tissue, these might still be picked up by conventional real-time PCR. We found that the numbers of viable tachyzoites were similar in controls and recNcROP2 and recNcMAG1 vaccinated groups, but significantly decreased in mice vaccinated with recNcPDI $(P<0.05)$ (Fig. 3).

\section{Humoral immune responses}

By ELISA, the sera of all mice exhibited a significant increase $(P<0.05)$ in $\mathrm{IgG}$ titres directed against the recombinant proteins these mice had been vaccinated with (data not shown). Fig. 4 shows the antibody responses following vaccination prior to infection (BI) and post-infection prior to euthanasia (PI) as assessed by ELISA employing crude $N$. caninum extract (Nc-antigen). Prior to infection (BI), total $\mathrm{IgG}$ reactive with $\mathrm{Nc}$-antigen was significantly

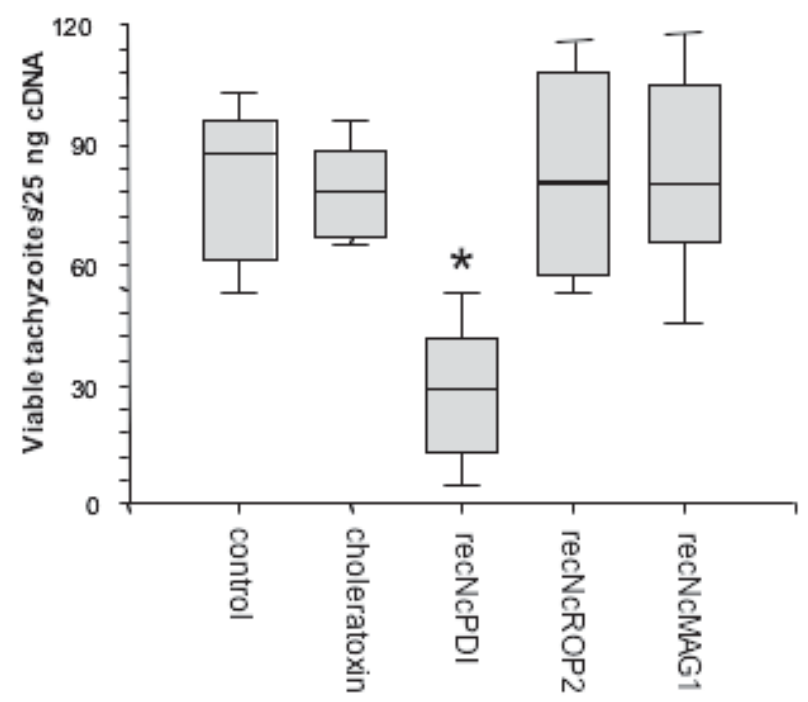

Fig. 3. Assessment of tachyzoite viability by detection and quantification of NcGRA2 transcripts in the brain tissues of the different treatment groups vaccinated by intra-nasal immunization with cholera toxin adjuvant. $*=P<0.05$ as compared to the cholera toxin-treated group. Error bars indicate S.D. Note the strongly reduced parasite viability detected in the recNcPDI vaccinated group.

$(P<0 \cdot 05)$ increased in all vaccinated mice compared to non-infected and adjuvant-control mice, no matter whether intraperitoneal or intra-nasal vaccination took place, and these levels increased significantly $(P<0 \cdot 05)$ in all animals following infection. IgG1 and IgG2a levels remained low before infection, but also mostly increased in post-infection sera, with few exceptions. First, in mice vaccinated intraperitoneally with recNcROP2, only IgG1 levels increased significantly $(P<0 \cdot 05)$ after infection, indicating that upon infection an IgG1-biased humoral response has taken place. In the corresponding intranasally vaccinated mice, both IgG1 and IgG2a levels increased significantly $(P<0 \cdot 05)$ (see 1 and $1^{\prime}$ in Fig. 4), resulting in similar protection levels in both cases. Secondly, mice immunized intraperitoneally with recNcMAG1 exhibited a significant $(P<0.05)$ increase of both $\operatorname{IgG1}$ and IgG2a after challenge, but in intra-nasally vaccinated mice, only $\operatorname{IgG} 2 \mathrm{a}$ was significantly $(P<0.05)$ elevated after infection, and this was associated with a high mortality postchallenge (see 2 and $2^{\prime}$ in Fig. 4). Thirdly, in recNcPDI-vaccinated mice, intraperitoneal as well as intra-nasal immunization and subsequent challenge infection also resulted in significant $(P<0.05)$ increase of both IgG1 and IgG2a, but in intraperitoneally vaccinated animals the values of $\operatorname{IgG} 2 \mathrm{a}$ were higher than those for IgG1, while in intranasally vaccinated mice, IgG1 levels were higher than those for IgG2a. The IgG1-values measured in i.p. vaccinated and infected mice were significantly lower compared to i.n. vaccinated mice $(P<0 \cdot 05)$, 


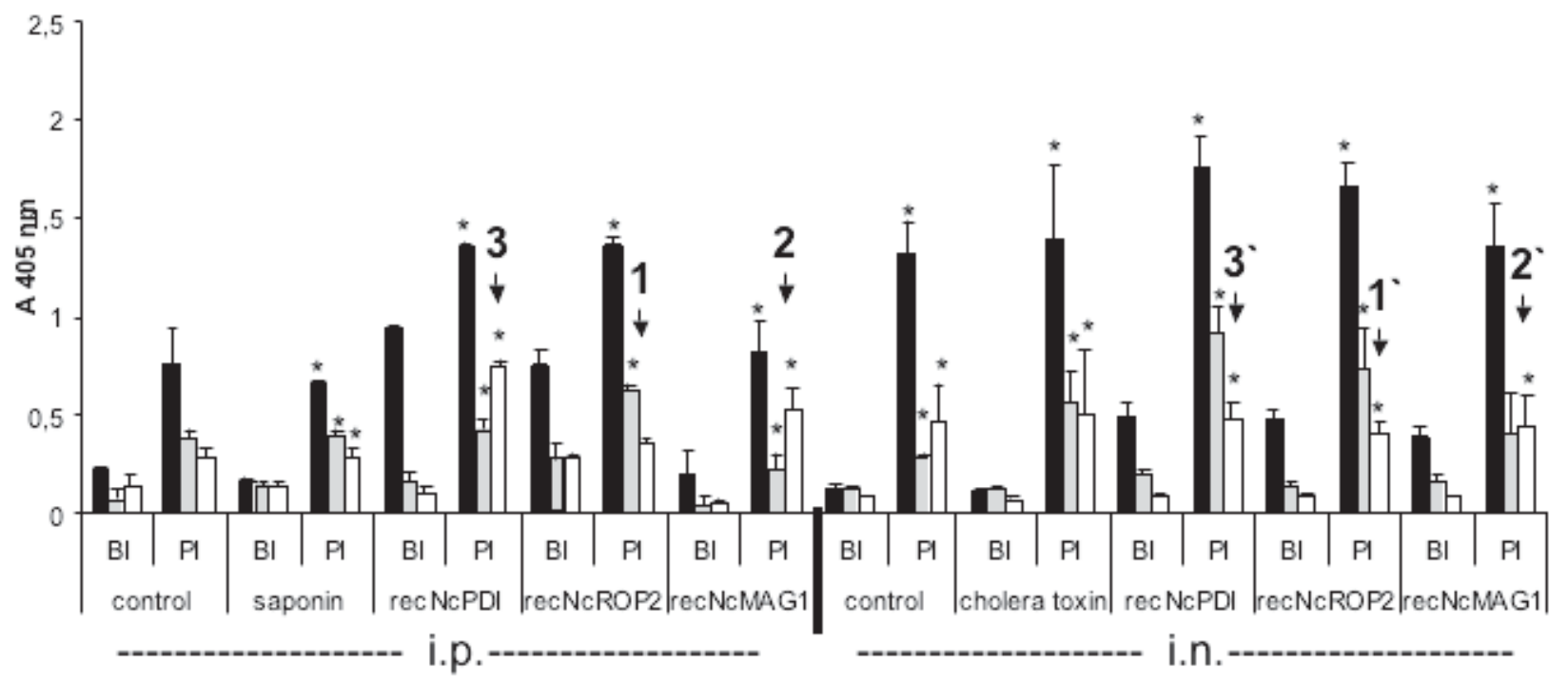

Fig. 4. Serological analysis (total $\operatorname{IgG}, \operatorname{IgG1}, \operatorname{IgG} 2 \mathrm{a}$ ) of all mice in all experimental groups. Serum samples were taken either following vaccination before infection (BI), or at the time of death following experimental infection (PI). ELISA wells were coated with $\mathrm{Nc}$-antigen. Mice were vaccinated intraperitoneally (i.p.) with antigens emulsified in saponin, or vaccinated intra-nasally (i.n.) with antigens emulsified in cholera toxin. 1 and 1 ' indicate that in mice vaccinated intraperitoneally with recNcROP2, only IgG1 - levels increased significantly after infection, while in the corresponding intra-nasally vaccinated mice, both IgG1 and IgG2a levels increased significantly. 2 and 2' indicate that mice immunized intraperitoneally with recNcMAG1 exhibited a significant increase of both IgG1 and IgG2a after challenge, but in intra-nasally vaccinated mice, only IgG2a was significantly elevated after infection. 3 and 3 ' indicate that in recNcPDI-vaccinated mice, intraperitoneal as well as intra-nasal immunization and subsequent challenge infection also resulted in significant increase of both $\mathrm{IgG1}$ and $\mathrm{IgG} 2 \mathrm{a}$, but in intraperitoneally vaccinated animals the values of $\mathrm{IgG} 2 \mathrm{a}$ were higher than those for IgG1, while in intra-nasally vaccinated mice, IgG1 levels were higher than those for IgG2a. $*=P<0 \cdot 05$ as compared to BI-sera.

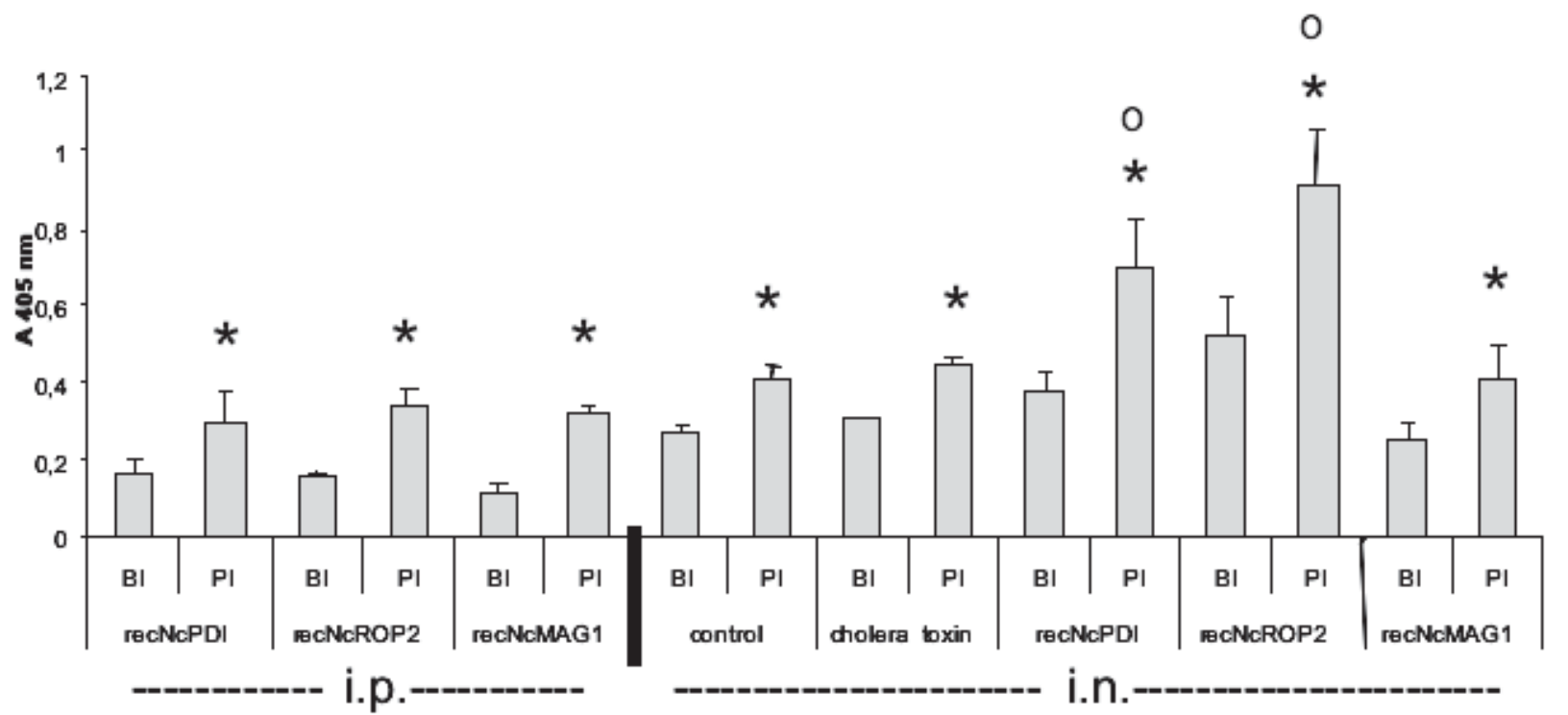

Fig. 5. Detection of IgA reacting with Nc-antigen by ELISA in sera in vaccinated mice; i.p.=intraperitoneal immunization, i.n. = intra-nasal immunization. $\mathrm{BI}=$ sera taken before infection, PI sera taken after infection prior to death. Error bars indicate s.D. ${ }^{*}=P<0.05$ when comparing the differences between BI and PI sera of each group; ${ }^{\circ}=P<0 \cdot 05$ as compared to the cholera toxin-treated group.

and the IgG2a-values in i.p. vaccinated and infected mice were significantly higher $(P<0 \cdot 05)$ compared to i.n. vaccinated mice (see 3 and $3^{\prime}$ in Fig. 4).
Sera from immunized and experimentally infected mice were also tested for the presence of IgA reactive with Nc-antigen (Fig. 5) In all groups, IgA levels 
increased following infection, but highly significant increase $(P<0 \cdot 01)$ in $\operatorname{IgA}$ was only visible in sera of mice vaccinated intra-nasally with NcROP2 and NcPDI.

\section{DISCUSSION}

In this study, we compared the efficacy of 3 distinct recombinant $N$. caninum antigens (NcROP2, NcMAG1 and NcPDI) against challenge infection with $N$. caninum tachyzoites in the C57BL/6 mouse cerebral infection model. For intraperitoneal vaccination, antigens were emulsified in saponin, for intra-nasal vaccination, antigens were suspended in cholera toxin. We here demonstrate that the efficacy of recNcROP2 vaccination was not dependent on the route of antigen delivery, while the efficacy of recNcMAG1 deteriorated upon intra-nasal application, and, in contrast, the efficacy of recNcPDI was highly enhanced. This study confirms earlier findings on intraperitoneally applied recNcROP2 that showed protection against both cerebral infection and fetal infection in mice, which was associated with a Th2-dominated immune response (Debache et al. 2008, 2009). Protection levels for NcROP2 in these earlier studies were higher compared to the experiments reported herein. On one hand, this could be explained by the slightly different age of the mice at the time-point of infection. On the other hand, there is, due to the nature of the parasite culture system, always the possibility of a certain degree of variation between individual experiments. In our study, we infected mice with $N$. caninum tachyzoites, which were freshly purified from in vitro-cultivated Vero cell monolayers, chosen at the moment of their putative highest infective stage (when most tachyzoites were still intracellular). Nevertheless, this time-point can be evaluated only qualitatively and it has been demonstrated earlier, that during extracellular maintenance of $N$. caninum tachyzoites will loose their infectivity within a few hours (Hemphill et al. 1996). Thus, a very small qualitative difference could be critical in terms of infectivity.

This study also showed that, in contrast to intraperitoneal delivery, intra-nasal application of recNcPDI resulted in strongly decreased cerebral parasite load, and in decreased numbers of viable tachyzoites in the brain. These effects were associated with an IgG1-biased humoral immune response in intra-nasally vaccinated mice as compared to intra-peritoneally vaccinated mice. This suggests that recNcPDI could represent a valuable vaccine candidate, if applied intra-nasally. Our findings confirm earlier studies on PDI in apicomplexan parasites. In human, natural IgA antibodies targeting Toxoplasma gondii PDI have been identified (Meek et al. 2002). Moreover, Liao et al. (2006) showed that NcPDI was present in excretory-secretory (ES) products, and that IgA antibodies obtained from individual cattle cattle tear samples recognized NcPDI. This suggested that the PDI-specific antibodies may be involved in defence against parasites. In addition, they confirmed earlier results (Naguleswaran et al. 2005; Müller et al. 2008) showing that PDI-specific inhibitors and NcPDI antiserum showed inhibitory effects on the growth of $N$. caninum tachyzoites in vitro, indicating that NcPDI could represent a valuable target for chemotherapy and/or vaccination.

To date, studies on protective immune responses against experimentally induced neosporosis in acute disease mouse models have produced conflicting results. On one hand, a number of investigations have emphasized that the protective effects of vaccines against challenge infection are associated with the development of a Th1-type immune response, dominated by $\operatorname{IgG} 2 \mathrm{a}$ antibody production, natural killer (NK) cell proliferation, and increased interferongamma production (Khan et al. 1997; Baszler et al. 1999; Ramamoorthy et al. $2007 a, b$; Klevar et al. 2007; Ellis et al. 2008). However, others have shown that both humoral and cell-mediated immune responses were important components of protective immunity against $N$. caninum (reviewed by Hemphill et al. 2006; Innes and Vermeulen, 2006; Williams et al. 2007), and demonstrated that protective immune responses in mice vaccinated with antigen lysate (Baszler et al. 2000) or with purified native NcSRS2 (Haldorson et al. 2005) were accompanied by increased IgG1 production, implying the involvement of a Th2-type response. Increased IgG1 antibody responses were also found upon vaccination of mice with recNcMIC3 and recNcMIC1, both of which resulted in reduced cerebral infection rates compared to those in non-vaccinated controls (Cannas et al. 2003 a; Alaeddine et al. 2005). Debache et al. (2008) showed that vaccination with recNcROP2 protected mice against acute neosporosis no matter whether an IgG1-biased (recNcROP2 emulsified in saponin adjuvants) or IgG2a-biased (recNcROP2 emulsified in Freunds adjuvants) humoral immune response was elicited. In addition, combined recNcROP2-NcMIC1NcMIC3 vaccination protected mice against fetal infection following challenge during pregnancy, in contrast to vaccination with individual antigens, and this effect was associated with a Th2-biased immune response associated with increased serum IgG1 responses and a high IL-4/interferon-gamma ratio (Debache et al. 2009). However, all these studies were carried out by applying vaccine candidates intraperitoneally or subcutaneously.

Another attractive route for vaccine administration is intra-nasal application. The nasal epithelium represents highly vascularized tissue with numerous microvilli, which increase the resorbing surface. There is little proteolytic activity in the intra-nasal cavity, and intra-nasal immunization 
stimulates both humoral and cellular immune responses, mucosally and systemically. Thus, immune responses can be induced also at distant sites owing to the dissemination of effector immune cells (Porgador et al. 1997: Arakawa et al. 2003, 2005; Hirunpetcharat et al. 1998; Pinto et al. 2004). Finally, upon intra-nasal vaccination, the antigen is deposited directly to the appropriate immunecompetent lymphoid tissues (Partidos et al. 2001; Byun, 2001). This results in the activation of T-cells, and the development of B-cells into IgA plasma cells (Partidos et al. 2001), resulting in a potentially efficient protection against acquired infection. Intranasal vaccination is, as for any immunization regimens, enhanced by the use of an appropriate adjuvant. We have here chosen cholera toxin produced by $V$. cholerae, since it is an effective mucosal adjuvant, which stimulates both Th1 - and Th2-type immune responses by co-stimulation of the antigenprimed CD4- and CD8-T cells. In addition, the antigen-specific CD4-T cell-mediated production of IL-2, IL-4 and interferon-gamma is enhanced (Debard et al. 1996).

There are different examples of how intra-nasal vaccination has led to protective immune responses against other non-mucosal, penetrative pathogens, including Plasmodium and Leishmania (Arakawa et al. 2003, 2005; Hirunpetcharat et al. 1998; Pinto et al. 2004). In addition, intra-nasal immunization with Toxoplasma gondii TgSAG1 and non-toxic heatlabile enterotoxins protected mice against challenge infection against T. gondii (Bonenfant et al. 2001), and recently Igarashi et al. (2007) showed that intranasal immunization in Balb/c mice with recombinant TgROP2, TgGRA5 and TgGRA7 applied with cholera toxin induced partial protection against tissue cyst formation after oral infection with Toxoplasma tissue cysts. Others have used intranasal immunization using $T$. gondii RNA in mice and demonstrated protection against challenge infection (Dimier-Poisson et al. 2006). Intra-nasal vaccination has also been applied in sheep, employing proteins from crude extracts of $T$. gondii encapsulated into poly(D, L-lactide-co-glycolide, resulting in humoral and cell-mediated immunity (Stanley et al. 2004). Others have demonstrated protective activity against oocyst shedding in cats vaccinated with crude rhoptry protein preparations via the intra-nasal route (Garcia et al. 2007).

In contrast to $T$. gondii, the mouse is not a natural host for $N$. caninum, and experimental infection does not mimic the natural infection route. Thus, when using the Nc-1 isolate, tissue cyst formation in mice has not been observed. The Nc-1-isolate will also not readily form tissue cysts in vitro (Vonlaufen et al. 2004; Risco-Castillo et al. 2004; Aguado-Martinez et al. 2009), and only rarely in inbred and outbred mice (Dubey and Lindsay, 1996), thus it is very likely that tachyzoite-to-bradyzoite stage conversion has not taken place in these mice. Therefore, the outcome of infection in our mouse model is most likely related to the viability status of tachyzoite-stage parasites. In this respect, we could demonstrate not only a reduced overall cerebral parasite burden in mice vaccinated intra-nasally with recNcPDI, but also a significantly reduced number of viable tachyzoites in that group.

The latter is intriguing: surprisingly, mice vaccinated with recNcROP2 exhibited a reduced overall cerebral parasite burden, but not a reduced number of viable parasites in the CNS compared with the control groups. These relative differences between overall parasite numbers and numbers of viable parasites in the different treatment groups can be explained by the extensive proliferation of tachyzoites in the CNS of unvaccinated control-group mice, which lead to an increased proportion of nonviable parasite organisms, and also resulted in death of all animals. In contrast, intra-nasal vaccination with recNcROP2 and recNcPDI kept the overall cerebral parasite burden at a lower level, but in the case of recNcROP2-vaccinated mice, those parasites reaching the brain tissue remained largely viable, while in the case of recNcPDI-vaccinated mice, the parasites could still be largely eliminated, once they had crossed the blood-brain barrier.

It is not known why intra-nasal application of recNcPDI induced protection, and application of the same protein via the intra-peritoneal route did not. Most likely though, the marked switch from an IgG2-dominated to a more prominent IgG1 isotype response against $\mathrm{Nc}$-antigen in intraperitoneally versus intra-nasally vaccinated animals could be detrimental to parasite survival, since a Th2-type response implies a lower expression of proinflammatory cytokines, and thus less immunopathology, and a higher chance for the host to clear or limit the infection by other immunological or physiological means. For recNcMAG1, the opposite effect could be noted, with intra-nasally vaccinated mice producing a significantly increased IgG2a response, which is indicative for a Th1-biased immune response, and this was associated with enhanced mortality in that group.

Clearly, further studies will be necessary to dissect these immunological and physiological events. However, our results are in line with those reported by Hiroi et al (1998), which showed that the nasalassociated lymphoid tissue is characterized by a Th0 environment, that can form a Th1 and/or Th2 phenotype, but the nasal passage was considered to be a Th2-dominant site with some Th1-type T cells, and humoral immunity leading to IgA production. Thus, in addition to a predominantly IgG1 response against $\mathrm{Nc}$-antigen, serum-IgA antibodies were also significantly elevated in the intra-nasally NcROP2 and NcPDI-vaccinated mice following challenge infection, but not in mice vaccinated with NcMAG1. 
It is conceivable that these additional antibodies could cause a more pronounced inhibition of parasite host cell invasion or replication. In addition, the close proximity of the intra-nasal cavity to the cerebral tissue might also provide additional protection against cerebral infection. All these factors, together with, most likely, a number of unknown parameters in the intra-nasally vaccinated mice, resulted in significantly decreased cerebral infection rates.

The fact that fewer viable tachyzoites could be detected in the brain tissues of mice vaccinated with recNcPDI indicates that parasites, once they have crossed the blood-brain barrier, could still be eliminated.

In conclusion, this report represents the first study on intra-nasal vaccination against $N$. caninum infection in mice, and our findings suggest that recNcPDI is a promising vaccine candidate and should be further considered for studies where the potential of this vaccine formulation for protection against fetal infection will be investigated.

\section{ACKNOWLEDGEMENTS}

We thank Norbert Müller, Joachim Müller, and Bruno Gottstein (Institute of Parasitology, University of Bern) for their support and critical evaluation of the data and the manuscript. This work was made possible through the National Science Foundation (grants No. 3100A0-112532 and 31-116257). C. G. and F. A. contributed equally to this work, and F.A. was supported through a grant provided by the Vetsuisse Faculty.

\section{REFERENCES}

Aguado-Martinez, A., Ortege-Mora, L. M., Alvarez-Garcia, G., Rodriguez-Marco, S., Risco-Castillo, V., Marugan-Hernandez, V. and Fernandez-Garcia, A. (2009). Stage-specific expression of NcSAG4 as a marker of chronic Neospora caninum infection in a mouse model. Parasitology 136, $757-764$

Alaeddine, F., Keller, N., Leepin, A. and Hemphill, A. (2005). Reduced infection and protection from clinical signs of cerebral neosporosis in C57BL/6 mice vaccinated with recombinant microneme antigen NcMIC1. Fournal of Parasitology 91, 657-665.

Arakawa, T., Tsuboi, T., Kishimoto, A., Sattabongkot, J., Suwanabun, N., Rungruang, T., Matsumoto, Y., Tsuji, N., Hisaeda, H., Stowers, A., Shimabukuro, I., Sato, Y. and Torii, M. (2003). Serum antibodies induced by intranasal immunization of mice with Plasmodium vivax Pvs25 coadministred with cholera toxin completely block parasite transmission to mosquitoes. Vaccine 21, 3143-3148.

Arakawa, T., Komesu, A., Otsuki, H., Sattanbongkot, J., Udomsangpetch, R., Matsumoto, Y., Tsuji, N., Wu, Y., Torii, M. and Tsuboi, T. (2005). Nasal immunization with a malaria transmission-blocking vaccine candidate; Pfs 25 induces complete protective immunity in mice against field isolates of Plasmodium falciparum. Infection and Immunity 73, 7375-7380.
Baszler, T. V., Long, M. T., McElwain, T. F. and Mathison, B. A. (1999). Interferon-gamma and interleukin-12 mediate protection to acute Neospora caninum infection in BALB/c mice. International Fournal for Parasitology 29, 1635-1646.

Baszler, T. V., McElwain, T. F. and Mathison, B. A. (2000). Immunization of BALB/c mice with killed Neospora caninum tachyzoite antigen induces a type 2 immune response and exacerbates encephalitis and neurological disease. Clinical and Diagnostic Laboroatory Immunology 7, 893-898.

Bonenfant, C., Dimier-Poisson, I., Velge-Roussel, F., Buzoni-Gatel, D., Del Giudice, G., Rappuoli, R. and Bout, D. (2001). Intranasal immunization with SAG1 and non-toxic mutant heat-labile enterotoxins protects mice against Toxoplasma gondii. Infection and Immunity 69, 1605-1612.

Byun, Y., Ohmura, M., Fijihashi, K., Yamamota, S., McGhee, J. R., Udaka, S., Kiyono, H., Takeda, Y., Kohsaka, T. and Yuki, Y. (2001). Nasal immunization with $E$. coli verotoxin 1 (VT1)-B subunit and a non-toxic mutant of cholera toxin elicits serum neutralizing antibodies. Vaccine 19, 2061-2070.

Cannas, A., Naguleswaran, A., Müller, N., Gottstein, B., Eperon, S. and Hemphill, A. (2003a). Vaccination of mice against experimental $N$. caninum infection using NcSAG1 - and NcSRS2-based recombinant antigens and DNA-vaccines. Parasitology 126, 303-312.

Cannas, A., Naguleswaran, A., Muller, N., Gottstein, B. and Hemphill, A. (2003b). Reduced cerebral infection of Neospora caninum-infected mice after vaccination with recombinant microneme protein NcMIC3 and ribi adjuvant. Fournal of Parasitology 89, 44-50.

Cho, J., Chung, W., Song, K., Na, B., Kang, S., Song, C. and Kim, T. (2005). Protective efficacy of vaccination with Neospora caninum multiple recombinant antigens against experimental Neospora caninum infection. Korean fournal for Parasitology 1, 19-25.

Debache, K., Alaeddine, F., Guionaud, C., Monney, T., Müller, J., Strohbusch, M., Leib, S. L., Grandgirard, D. and Hemphill, A. (2009). Vaccination with recombinant NcROP2 combined with recombinant $\mathrm{NcMIC} 1$ and $\mathrm{NcMIC} 3$ reduces cerebral infection and vertical transmission in mice experimentally infected with Neospora caninum tachyzoites. International Fournal for Parasitology May 15: Epub ahead of print

Debache, K., Guionaud, C., Alaeddine, F., Mevissen, M. and Hemphill, A. (2008). Vaccination of mice with recombinant NcROP2 antigen reduces mortality and cerebral infection in mice infected with Neospora caninum tachyzoites, International Fournal for Parasitology 38, 1455-1463.

Dimier-Poisson, I., Aline, F., Bout, D. and Mevelec, M. N. (2006). Induction of protective immunity against toxoplasmosis in mice by immunization with Toxoplasma RNA. Vaccine 24, 1705-1709.

Dubey, J. P., Hattel, A. L., Lindsay, D. S. and Topper, M. J. (1988). Neonatal Neospora caninum infection in dogs: isolation of the causative agent and experimental transmission. Fournal of the American Veterinary Medical Association 193, 1259-1263. 
Dubey, J. P. and Lindsay, D. S. (1996). A review of Neospora caninum and neosporosis. Veterinary Parasitology 67, 1-59.

Dubey, J. P., Schares, G. and Ortega, L. M. (2007). Epidemiology and control of neosporosis and Neospora caninum. Clinical Microbiology. Microbiology Reviews 20, 323-367.

Ellis, J. T., Miller, C., Quinn, H., Ryce, C. and Reichel, M. P. (2008). Evaluation of recombinant proteins of Neospora caninum as vaccine candidates (in a mouse model). Vaccine 26, 5989-5996.

Garcia, J. L., Navarro, I. T., Biazzono, L., Freire, R. L., da Silva Guimaraes, J., Cryssafidis, A. L., Bugni, F. M., Leme da Cunha, I. A., Hamada, F. N. and Ferriera Dias, R. C. (2007). Protective activity against oocyst shedding in cats vaccinated with crude rhoptry proteins of the Toxoplasma gondii by the intranasal route. Veterinary Parasitology 145, 197-206.

Gondim, L. F., McAllister, M. M., Pitt, W. C. and Zemlicka, D. E. (2004). Coyotes (Canis latrans) are definitive hosts of Neospora caninum. International Fournal for Parasitology 34, 159-161.

Haldorson, G. J., Mathison, B. A., Wenberg, K., Conrad, P. A., Dubey, J. P., Trees, A. J., Yamane, I. and Baszler, T. V. (2005). Immunization with native surface protein NcSRS2 induces a Th2 immune response and reduces congenital Neospora caninum transmission in mice. International fournal for Parasitology 35, 1407-1415.

Hemphill, A., Gottstein, B. and Kaufmann, H. (1996). Adhesion and invasion of bovine endothelial cells by Neospora caninum. Parasitology 112, 183-197.

Hemphill, A., Vonlaufen, N. and Naguleswaran, A. (2006). Cellular and immunological basis of the host-parasite relationship during infection with Neospora caninum. Parasitology 133, 261-278.

Hirunpetcharat, C., Stanisic, D., Liu, X. Q., Vadolas, J., Strugnell, R. A., Lee, R., Miller, L. H., Kaslow, D. C. and Good, M. F. (1998). Intranasal immunization with yeast-expressed $19 \mathrm{kDa}$ carboxyl-terminal fragment of Plasmodium yoelii merozoite surface protein1 (yMSP119) induces protective immunity to blood stage malaria infection in mice. Parasite Immunology 20, 413-420.

Hiroi, T., Iwatani, K., Iijima, H., Kodama, S., Yanagita, M. and Kiyono, H. (1998). Nasal immune system: distinctive Th0 and Th1/Th2 type environments in murine nasal-associated lymphoid tissues and nasal passage, respectively. European Fournal of Immunology 28, 3346-3353.

Igarashi, M., Kano, F., Tamekun, i K., Machado, R. Z., Navarro, I. T., Vidotto, O., Vidotto, M. C. and Garcia, J. L. (2007). Toxoplasma gondii: Evaluation of an intranasal vaccine using recombinant proteins against brain cyst formation in BALB/c mice. Experimental Parasitology 118, 386-392

Innes, E. A. (2007). The host-parasite relationship in pregnant cattle infected with Neospora caninum. Parasitology 134, 1903-1910.

Innes, E. A. and Mattsson, J. G. (2007). Neospora caninum emerges from the shadow of Toxoplasma gondii. Trends in Parasitology 23, 43-44.

Innes, E. A. and Vermeulen, A. N. (2006). Vaccination as a control strategy against the coccidial parasites
Eimeria, Toxoplasma and Neospora. Parasitology 133, S145-S168.

Khan, I. A., Schwartzman, J. D., Fonseka, S. and Kasper, L. H. (1997). Neospora caninum: role of immune cytokines in host immunity. Experimental Parasitology 85, 23-34.

Klevar, S., Kulberg, S., Boysen, P., Storset, A. K., Moldal, T., Bjorkman, C. and Olsen, I. (2007). Natural killer cells act as early responders in an experimental infection with Neospora caninum in calves. International Fournal for Parasitology 37, 329-339.

Liao, M., Ma, L., Bannai, H., Lee, E. G., Xie, Z., Tang, $X$., Zhang, H., Xuan, $X$. and Fujisaki, $K$. (2006). Identification of a protein disulfide isomerase of Neospora caninum in excretory-secretory products and its IgA binding and enzymatic activities. Veterinary Parasitology 139, 47-56.

Liddell, S., Jenkins, M. C., Collica, C. M. and Dubey, J. P. (1999). Prevention of vertical transfer of Neospora caninum in BALB/c mice by vaccination. Fournal of Parasitology 85, 1072-1075.

McAllister, M. M., Dubey, J. P., Lindsay, D. S., Jolley, W. R., Wills, R. A. and McGuire, A. M. (1998). Dogs are definitive hosts of Neospora caninum. International Fournal for Parasitology 28, 1473-1478.

Meek, B., Back, J. W., Klaren, V. N., Speijer, D. and Peek, R. (2002). Protein disulfide isomerase of Toxoplasma gondii is targeted by mucosal IgA antibodies in humans. FEBS Letters 522, 104-108.

Müller, J., Naguleswaran, A., Nüller, N. and Hemphill, A. (2008). Neospora caninum: functional inhibition of protein disulfide isomerase by the broad-spectrum anti-parasitic drug nitazoxanide and other thiazolides. Experminental Parasitology 118, $80-88$.

Müller, N., Vonlaufen, N., Gianinazzi, C., Leib, S. L. and Hemphill, A. (2002). Application of real time fluorescent PCR for quantitative assessment of Neospora caninum infections in organotypic slice cultures of rat central nervous tissue. Fournal of Clinical Microbiology 40, 252-255.

Naguleswaran, A., Alaeddine, F., Guionaud, C., Vonlaufen, N., Sonda, S., Jenoe, P., Mevissen, M. and Hemphill, A. (2005). Neospora caninum protein disulfide isomerase is involved in tachyzoite-host cell interaction. International Fournal for Parasitology 35, 1459-1472.

Parmley, S. F., Yang, S., Harth, G., Sibley, L. D., Sucharczuk, A. and Remington, J. S. (1994). Molecular characterization of a 65 kilodalton Toxoplasma gondii antigen expressed abundantly in the matrix of tissue cysts. Molecular and Biochemical Parasitology 66, 283-296.

Partidos, C. D., Beignon, A.-S., Semetey, V., Briand, J.-P. and Muller, S. (2001). The bare skin and the nose as non-invasive routes for administering peptide vaccines. Vaccine 19, 2708-2715.

Porgador, A., Staats, H. F., Faiola, B., Gilboa, E. and Palker, T. J. (1997). Intranasal immunization with CTL epitope peptides from HIV-1 or ovalbumin and the mucosal adjuvant cholera toxin induces peptide-specific CTLs and protection against tumor development in vivo. Fournal of Immunology 158, 834-841. 
Pinto, E. F., Pinheiro, R. O., Rayol, A., Larraga, V. and Rossi-Bergmann, B. (2004). Intranasal vaccination against cutaneous leishmaniasis with a particulated leishmanial antigen or DNA encoding LACK. Infection and Immunity 72, 4521-4527.

Ramamoorthy, S., Sanakkayala, N., Vemulapalli, R., Duncan, R. B., Lindsay, D. S., Schurig, G. S., Boyle, S. M., Kasimanickam, R. and Sriranganathan, N. $(2007 b)$. Prevention of lethal experimental infection of $\mathrm{C} 57 \mathrm{BL} / 6$ mice by vaccination with Brucella abortus strain RB51 expressing Neospora caninum antigens. International Fournal for Parasitology 37, 1521-1529.

Ramamoorthy, S., Sanakkayala, N., Vemulapalli, R., Jain, N., Lindsay, D. S., Schurig, G. S., Boyle, S. M. and Sriranganathan, N. (2007a). Prevention of vertical transmission of Neospora caninum in C57BL/6 mice vaccinated with Brucella abortus strain RB51 expressing $N$. caninum protective antigens. International Fournal for Parasitology 37, 1531-1538.

Risco-Castillo, V., Fernández-Garcia, A. and Ortega-Mora, L. M. (2004). Comparative analysis of stress agents in a simplified in vitro system of Neospora caninum bradyzoite production. Fournal of Parasitology 90, 466-470.

Srinivasan, S., Müller, J., Suana, A. and Hemphill, A. (2007). Vaccination with microneme protein NcMIC4 increases mortality in mice inoculated with Neospora caninum. Parasitology 92, 1235-1243.
Stanley, A. C., Buxton, D., Innes, E. A. and Huntley, J. F. (2004). Intranasal immunisation with Toxoplasma gondii tachyzoite antigen encapsulated into PLG microspheres induces humoral and cell mediated immunity in sheep. Vaccine 22, 3929-3941.

Strohbusch, M., Müller, N., Hemphill, A., Greif, G. and Gottstein, B. (2008a). NcGRA2 as a molecular target to assess the parasiticidal activity of toltrazuril against Neospora caninum. Parasitology 135, 1065-1073.

Strohbusch, M., Müller, N., Hemphill, A., Greif, G. and Gottstein, B. $(2008 b)$. NcGRA2-RT-PCR to detect live versus dead parasites in Neospora caninum infected mice. The Open Parasitology Fournal 2, 64-68.

Vonlaufen, N., Guetg, N., Naguleswaran, A., Müller, N., Björkman, C., Schares, G., von Blumröder, D., Ellis, J. and Hemphill, A. (2004). In vitro induction of Neospora caninum bradyzoites in Vero cells reveals differential antigen expression, localization, and host cell recognition of tachyzoites and bradyzoites. Infection and Immunity 72, 576-583.

Williams, D. J. L. and Trees, A. J. (2006). Protecting babies: vaccine strategies to prevent foetal infection in Neospora caninum infected cattle. Parasite Immunology 28, 61-67.

Williams, D. J., Guy, C. S., Smith, R. F., Ellis, J. T., Björkman, C., Reichel, M. P. and Trees, A. J. (2007). Immunization of cattle with live tachyzoites of Neospora caninum confers protection against fetal death. Infection and Immunity 75, 1343-1348. 